\title{
Assessment of Availability, Utilization and Quality of Emergency Obstetric Care in 2014 at Hai District, Northern Tanzania
}

\author{
Rahma Muhammad Bakari ${ }^{1}$, Damian Jeremia Damian ${ }^{2,3}$, Patricia Swai ${ }^{4}$, Ahmad Mohamed \\ Makuwani $^{5}$, Michael Johnson Mahande ${ }^{2}$, Sia Emmanueli Msuya ${ }^{2,3}$, * \\ ${ }^{1}$ Kilimanjaro Christian Medical University College (KCMU Co), Moshi, Tanzania \\ ${ }^{2}$ Insitute of Public Health, Department of Epidemiology and Biostatistics, KCMU Co, Moshi, Tanzania \\ ${ }^{3}$ Institute of Public Health, Department of Community Medicine, KCMC Hospital and KCMU Co, Moshi, Tanzania \\ ${ }^{4}$ Department of Obstetrics and Gynecology, KCMC Hospital and KCMU Co, Moshi, Tanzania \\ ${ }^{5} \mathrm{RCH}$ Section, Ministry of Health and Social Welfare, Dar es Salaam, Tanzania

\section{Email addresses:} \\ bakari_rmb@yahoo.com (R. M. Bakari),d_jeremy5@yahoo.com (D. J. Damian), patriciaswai@yahoo.com (P. Swai), \\ amakuwani@gmail.com (A. M. Makuwani),jmmahande@gmail.com (M. J. Mahande), siamsuya@hotmail.com (S. E. Msuya)
}

\section{To cite this article:}

Rahma Muhammad Bakari, Damian Jeremia Damian, Patricia Swai, Ahmad Mohamed Makuwani, Michael Johnson Mahande, Sia Emmanueli Msuya. Assessment of Availability, Utilization and Quality of Emergency Obstetric Care in 2014 at Hai District, Northern Tanzania. Journal of Gynecology and Obstetrics. Vol. 3, No. 3, 2015, pp. 43-48. doi: 10.11648/j.jgo.20150303.11

\begin{abstract}
Background: Availability of emergency obstetric and newborn care (EmOC) is one of interventions to reduce maternal and newborn deaths. Maternal and newborn mortality is a public health problem in most developing countries including Tanzania. In these settings, coverage of EmOC is low especially in rural areas, with limited information on availability and use of EmOC services. Objectives: To assess the availability, utilization and quality of emergency obstetric care in Hai district, located at Kilimanjaro region, northern Tanzania. Methods: A cross-sectional survey of 12 health facilities ( 2 hospitals and 10 primary health care facilities) which provide delivery services in the district was conducted in May- June 2014. Modified AMDD data collection tool was used and it assessed availability of services, supplies and equipments, infrastructure and actual performance of EmOC within the past 3 months prior to the interview. Proportions were used to summarize the data. Results: The two comprehensive EmOC facilities (CEmOC) could provide all the nine required signal functions while none of the basic EmOC facilities (BEmOC) could provide the seven required signal functions. For a population of 214,454 in the district, the total number of health facilities designated to provide EmOC services exceeded the minimum required number which was 1 for $\mathrm{CEmOC}$ and $2 \mathrm{BEmOC}$. The proportion of births taking place in facilities was $65.3 \%$ and the met need for emergency obstetric complications was $94.5 \%$. Population based caesarean section rate and the still birth rate were $7.4 \%$ and $1.3 \%$ respectively. Conclusion: BEmOC facilities, which are the first level of care for majority of women and newborns with complications, need to be strengthened to offer the required medical and surgical interventions to save lives. There is a need to scale-up training of health providers especially at the lower level (dispensaries and health centres) in EmOC as well as to strength supply chain system in order to contribute in attaining the national BEmOC coverage of $70 \%$ by December 2015.
\end{abstract}

Keywords: Emergency Obstetric Care, UN Process Indicators, Maternal Mortality, Tanzania

\section{Introduction}

Improving maternal health is among the millennium development goals (MDGs) which were adopted in September 2000 by the international community where by under MDG 5, countries agreed to have a $3 / 4$ reduction in maternal mortality ratio by the year 2015 [1].

Approximately 289,000 women die globally every year due to pregnancy complications [1]. Direct obstetric complications like bleeding, hypertensive disorders of pregnancy, sepsis, complications of abortions, ruptured uterus and ectopic pregnancy contributes nearly $70 \%$ of the deaths [2]. Almost (98\%) of these maternal deaths do occur 
in developing countries, but are preventable if they are timely recognized and treated $[1,2]$. Globally maternal mortality ratio (MMR) has declined by nearly 50\% from 1990 to 2012 and in Sub Saharan Africa (SSA) by 41\%; from 920 deaths per 100,000 live births in 1990 to 500 deaths per 100,000 births in 2010 [1, 3]. In Tanzania, MMR has declined from 578 maternal deaths per 100,000 live births in 2004-05 to 410 in 2014, but the target was to reach less than 200 maternal deaths per 100,000 live births by December 2015 [1, $4-6]$.

One of the evidence-based interventions to reduce maternal and newborn morbidity and mortality is to improve the availability, accessibility, utilization and quality of services for the treatment of complications that arise during pregnancy and childbirth. These services are collectively known as Emergency Obstetric Care (EmOC) and are should be offered by skilled birth attendants [7. 8]. Most of maternal complications are unpredictable and when they do occur it is only access to facilities that have skilled attendants (SBA) and ability to detect timely and manage the complications that can save lives.

Table 1. EmOC signal functions and UN Process Indicators.

\begin{tabular}{|c|c|}
\hline $\begin{array}{l}\text { Levels of EmONC and their } \\
\text { signal functions }\end{array}$ & $\begin{array}{l}\text { Process indicators for M\&E of } \\
\text { the availability, accessibility, } \\
\text { utilization and quality of } \\
\text { EmONC }\end{array}$ \\
\hline $\begin{array}{l}\text { BEmOC } \\
\text { Parenteral antibiotics to treat sepsis } \\
\text { Parenteral oxytocics to treat } \\
\text { hemorrhage } \\
\text { Parenteral anticonvulsants to treat } \\
\text { pre-eclampsia and eclampsia } \\
\text { Manual removal of retained } \\
\text { placenta } \\
\text { Removal of retained products of } \\
\text { conception by manual vacuum } \\
\text { aspiration (MVA) } \\
\text { Assisted vaginal delivery (vacuum } \\
\text { extraction) } \\
\text { Newborn resuscitation using bag } \\
\text { and mask }\end{array}$ & $\begin{array}{l}\text { 1. Availability of EmOC facilities } \\
\text { per } 500,000 \text { population ( } 5 \text { EmOC } \\
\text { facilities per } 500,000 \text { people, and } \\
\text { at least } 1 \text { CEmOC) } \\
\text { 2. Geographical distribution of } \\
\text { EmOC facilities } \\
\text { 3. Proportion of all births } \\
\text { conducted in EmOC facilities (at } \\
\text { least } 15 \% \text { ) } \\
\text { 4. Met need for EmOC (Proportion } \\
\text { of women who have emergency } \\
\text { obstetric complications who are } \\
\text { treated in the EmOC facilities - } \\
100 \% \text { ) } \\
\text { 5. Caeserian section as proportion } \\
\text { of births in the population (5-15\%) } \\
\text { 6. Case fatality rate of direct } \\
\text { obstetric complications treated at } \\
\text { EmOC facilities (<1\%) } \\
\text { 7. Early neonatal deaths }\end{array}$ \\
\hline
\end{tabular}

Source: WHO, 2009

Emergency Obstetric Care is divided into two levels of care: Basic Emergency Obstetric Care (BEmOC) and Comprehensive Emergency Obstetric Care (BEmOC), (Table 1). An EmOC facility is one which provides life-saving medical or surgical interventions known as 'signal functions". Basic EmOC should provide 7 signal functions and is provided at lower level health facilities like dispensaries and health centers. A Comprehensive EmOC facility is one which provides all of the BEmOC signal functions and in addition is able to offer blood transfusion and Caesarean Section $(\mathrm{C} / \mathrm{S})$. CEmOC is usually provided at hospital level and some upgraded health centres [7].

The 2009 WHO guidelines recommended that for every 500,000 people there should be five EmOC facilities; four offering basic EmOC and one should be a comprehensive EmOC facility [7]. The coverage of CEmOC in Tanzania was reported to be $64.5 \%$ in 2006 and it increased to $73 \%$ in 2012 [9]. The coverage of BEmOC is low; $20 \%$ of the dispensaries and $39 \%$ of health centres could provide the seven signal functions of obstetric emergency in 2012 [10]. Target for the country is to have $100 \%$ of hospitals providing all the 9 signal functions of EmOC and $70 \%$ of the dispensaries and health centres providing the 7 signal functions by December $2015[5,11]$.

Availability, utilization and quality of EmOC is measured by using the United Nations process indicators (Table 1) [7]. Number of EmOC facilities per 500000 population and the geographical distribution of these facilities assess availability of services. Proportion of births at EmOC facilities, met need for $\mathrm{EmOC}$ and population based $\mathrm{C} / \mathrm{S}$ rate are measures of utilization of EmOC. Case Fatality Rate (CFR) and early neonatal deaths assess quality of EmOC offered. The recommended level for each indicator is shown in Table 1.

While there is national data on coverage of EmOC, there is no information at the district level on coverage of EmOC. This study aimed to describe the availability, utilization and quality of EmOC at health facilities with delivery services in Hai district, northern Tanzania.

\section{Materials and Methods}

This was a cross sectional survey conducted in May - June 2014 at health facilities with delivery services in Hai District. Hai is one of the seven districts of Kilimanjaro region with a population of 214,454 [12]. Nearly $75 \%$ of the region population lives in the rural area. The region has high attendance in reproductive and child health services; antenatal care coverage is at $100 \%$, skilled birth attendance use during delivery $86 \%$ and postnatal care coverage of $48 \%$ compared to the nation level of $96 \%, 51 \%$ and $31 \%$ respectively [6].

In Tanzania, the health care system is organized into 4 levels; $1^{\text {st }}$ level is dispensaries supposed to serve 5,000 10,000 people referring cases to health centres supposed to serve approximately 50,000 people. The $3^{\text {rd }}$ level is district hospitals serving about 250,000 people and referring cases to regional or referral hospitals [13]. All the hospitals are expected to provide $\mathrm{CEmOC}$ while dispensaries and health centres with delivery services are expected to offer BEmOC. Hai district has a total of 62 health facilities; 2 hospitals, 6 health centres and 54 dispensaries. Of these 44 provide delivery services i.e. 2 hospitals, 5 health centers and 37 dispensaries. The study included all the 2 hospitals, 5 health centres and 5 dispensaries. The five dispensaries were 
purposive selected because they were the ones with highest number of deliveries i.e. had at least more than 10 deliveries per month.

Health facility assessment tool based on the UN EmOC assessment manual and criteria was used for data collection [7]. Selected health facilities were visited and interviews were conducted with the person(s) in charge of the maternity unit. Registers from the labour ward and gynaecology ward were reviewed. Information on performance of signal functions, number of deliveries, identified obstetric complications, maternal deaths and stillbirths was collected for the period of three months prior to the interviews (February - April 2014). Direct observation using a checklist was used to assess for availability of supplies and equipments for performing EmOC and newborn services.

Proportions were used to summarize the results for different indicators. Based on the UN process indicators, population measures for the availability and utilization of EmOC were calculated.

Ethical clearance was sought from the Kilimanjaro Christian Medical University College Ethical committee before starting the research. Permission to conduct research was obtained from Hai District Medical Officer and the Medical Officer In charge of every health facility surveyed.

\section{Results}

Table 2. EmOC signal functions performed at different levels of facilities in the past 3 months (February-April, 2014) prior to the study in Hai District.

\begin{tabular}{|c|c|c|c|c|c|c|c|c|c|c|c|}
\hline Level & $\mathbf{N}$ & $\begin{array}{l}\mathrm{I} / \mathrm{M} \text { or } \mathrm{I} / \mathrm{V} \\
\text { antibiotics }\end{array}$ & $\begin{array}{l}\text { I/M or } \\
\text { I/V } \\
\text { oxytocics }\end{array}$ & $\begin{array}{l}\text { I/M or } \\
\text { I/V } \\
\text { anticonv } \\
\text { ulsant }\end{array}$ & $\begin{array}{l}\text { Manual } \\
\text { removal } \\
\text { of } \\
\text { placenta }\end{array}$ & $\begin{array}{l}\text { Removal } \\
\text { of } \\
\text { retained } \\
\text { products } \\
\text { (MVA) }\end{array}$ & $\begin{array}{l}\text { Assisted } \\
\text { vaginal } \\
\text { delivery } \\
\text { (Vacuum) }\end{array}$ & $\begin{array}{l}\text { Neonatal } \\
\text { resuscitat } \\
\text { ion }\end{array}$ & $\begin{array}{l}\text { Caesare } \\
\text { an } \\
\text { section }\end{array}$ & $\begin{array}{l}\text { Blood } \\
\text { transfusi } \\
\text { on }\end{array}$ & $\begin{array}{l}\text { Fully } \\
\text { functiona } \\
\text { I EmOC }\end{array}$ \\
\hline $\begin{array}{l}\text { Hospitals } \\
\text { (CEmOC) } \\
\text { Health }\end{array}$ & 2 & $2 / 2$ & $2 / 2$ & $2 / 2$ & $2 / 2$ & $2 / 2$ & $2 / 2$ & $2 / 2$ & $2 / 2$ & $2 / 2$ & $2 / 2$ \\
\hline $\begin{array}{l}\text { Centres } \\
(\mathrm{BEmOC})\end{array}$ & 5 & $5 / 5$ & $5 / 5$ & $2 / 5$ & $0 / 5$ & $0 / 5$ & $0 / 5$ & $1 / 5$ & N/A & N/A & $0 / 5$ \\
\hline $\begin{array}{l}\text { Dispensaries } \\
(\mathrm{BEmOC})\end{array}$ & 5 & $5 / 5$ & $5 / 5$ & $0 / 5$ & $0 / 5$ & $0 / 5$ & $0 / 5$ & $0 / 5$ & N/A & N/A & $0 / 5$ \\
\hline Total & 12 & $12 / 12$ & $12 / 12$ & $4 / 12$ & $2 / 12$ & $2 / 12$ & $2 / 12$ & $2 / 12$ & & & $2 / 12$ \\
\hline
\end{tabular}

NA: Not applicable because it is a BEmOC facility

Table 3. Utilization and quality of EOC services in the past three months (February-April) prior to the study in Hai District, 2014.

\begin{tabular}{ll}
\hline Variable & Number or percentage \\
\hline Total Population of the district & 214,454 \\
Expected number of births per year ${ }^{1}$ & 5361 \\
Recorded number of births in the assessed facilities & 3500 \\
Proportion of expected births taking place in assessed facilities & $65.3 \%$ \\
Number of women expected to have obstetrics complications per year ${ }^{2}$ & 804 \\
Number of EOC complications recorded in assessed facility per year & 760 \\
Met need for EOC ${ }^{3}$ & $94.5 \%$ \\
Recorded number of caesarean section per year & 396 \\
Population based caesarean section rate ${ }^{4}$ & $7.4 \%$ \\
Number of recorded maternal deaths in assessed facilities per year & 0 \\
Number of recorded still births per year & 68 \\
Facility based still birth rate & 5 \\
\hline
\end{tabular}

A total of 12 health facilities participated; 2 designated as comprehensive EmOC facilities and 10 as basic EmOC facilities.

\subsection{Availability of EmOC Signal Functions}

The two hospitals could offer all the 9 EmOC signal functions required, while none of the BEmOC facilities could offer the 7 required signal functions, Table 2. Administration of parenteral antibiotics and uterotonic drugs were universally available at all levels. Signal functions which required special skills like manual removal of placenta, removal of retained products and newborn resuscitation were non-existent in BEmOC facilities. Magnesium sulphate was available in two out of ten BEmOC facilities. The main reasons for non performance of the signal functions were lack of necessary equipments and cases.

\subsection{Availability of Facilities Providing EmOC}

According to the UN recommendations, there should be at least one comprehensive and four basic EmOC facilities per 500,000 population. Hai district with a total population of 214,454 required $1 \mathrm{CEmOC}$ facility and 2 BEmOC facilities. In terms of number of health facilities, the district has excess number of $\mathrm{CEmOC}$ and $\mathrm{BEmOC}$ facilities, but in terms of functionality the BEmOC facilities were limited. 
${ }^{1}$ Calculated by multiplying total population*crude birth rate.

${ }^{2}$ Estimated as $15 \%$ of all expected births in the district.

${ }^{3}$ Number of women who were admitted to the facility with EmOC complications divided by expected EmOC complications.

${ }^{4}$ Number of caesarean section performed as \% of expected births in the district.

${ }^{5}$ Number of stillbirths as a proportion of total deliveries.

\subsection{Utilisation of EmOC}

The proportion of expected births which occurred in the assessed health facilities was $65.3 \%$ of all births in the districts. According to UN Indicators, expected population need for EmOC is based on the assumption that $15 \%$ of expected deliveries will end up with complications. Met need for EmOC in the district was $94.5 \%$, Table 3. The district population based caesarean section $(\mathrm{C} / \mathrm{S})$ rate was $7.3 \%$.

\subsection{Quality of EmOC}

Quality of services provided by health facilities is measured by Case Fatality Rate which is number of women who died out of those with recorded obstetric complications. None of the health facilities had maternal deaths records in the past 3 months prior to assessment. Stillbirth rate was $1.3 \%$.

Adequate availability of trained staff is essential for providing quality services. There were nine different cadres of staff working in maternity care and conducting deliveries in the district, Table 4. All the nine cadres conducted deliveries regardless of the level of health facility. None of the hospitals had a specialist doctors i.e. obstetricians, paediatricians or anaesthetists.

Table 4. Cadre of staff available in assessed facilities and conducting delivery services in Hai District, 2014.

\begin{tabular}{|c|c|c|c|c|c|c|}
\hline \multirow[t]{2}{*}{ CADRE } & \multirow[t]{2}{*}{$\mathbf{N}$} & \multicolumn{2}{|c|}{$\begin{array}{l}\text { Level of health facility where } \\
\text { cadre present }\end{array}$} & \multirow[b]{2}{*}{ Dispensary } & \multirow[t]{2}{*}{$\begin{array}{l}\text { Conducting } \\
\text { Deliveries }\end{array}$} & \multirow[t]{2}{*}{$\begin{array}{l}\text { Conducting } \\
\text { Deliveries (\%) } \\
\end{array}$} \\
\hline & & Hospital & Health centre & & & \\
\hline Medical doctor & 8 & $\mathrm{X}$ & $\mathrm{N}$ & $\mathrm{N}$ & $\mathrm{X}$ & $8(100)$ \\
\hline $\begin{array}{l}\text { Assistant Medical } \\
\text { Officer }\end{array}$ & 7 & $\mathrm{X}$ & $\mathrm{X}$ & $X$ & $\mathrm{X}$ & $7(100)$ \\
\hline Clinical Officer & 21 & $\mathrm{X}$ & $\mathrm{X}$ & $\mathrm{X}$ & $\mathrm{X}$ & $21(100)$ \\
\hline $\begin{array}{l}\text { Registered Nurse } \\
\text { Midwife }\end{array}$ & 57 & $\mathrm{X}$ & $\mathrm{X}$ & $X$ & $\mathrm{X}$ & $57(100)$ \\
\hline $\begin{array}{l}\text { Enrolled Nurse } \\
\text { Midwife }\end{array}$ & 42 & $\mathrm{X}$ & $\mathrm{X}$ & $\mathrm{X}$ & $\mathrm{X}$ & $42(100)$ \\
\hline $\begin{array}{l}\text { Public Health } \\
\text { Nurse }\end{array}$ & 6 & $\mathrm{X}$ & $\mathrm{X}$ & $\mathrm{X}$ & $\mathrm{X}$ & $3(50)$ \\
\hline $\begin{array}{l}\text { Maternal and Child } \\
\text { Health Aide (MCHA) }\end{array}$ & 14 & $\mathrm{X}$ & $\mathrm{X}$ & $\mathrm{X}$ & $\mathrm{X}$ & $14(100)$ \\
\hline Student Nurse & 141 & $X$ & N/A & N/A & $\mathrm{X}$ & $141(100)$ \\
\hline Nurse Attendant & 85 & $\mathrm{X}$ & $\mathrm{X}$ & $\mathrm{X}$ & $\mathrm{X}$ & $43(50.5)$ \\
\hline Total & 381 & & & & & $296(77.7)$ \\
\hline
\end{tabular}

$\mathrm{X}$ : present or yes; $\mathrm{N}$ - cadre not present in the facility

\section{Discussion}

The key findings of the study showed that the availability of basic EmOC services in this rural district is still very limited. However utilization of facilities for EmOC was high; met need for EmOC was $94 \%$ and population based $\mathrm{C} / \mathrm{S}$ rate of $7 \%$.

The number of physical structures/ health facilities designated to offer BEmOC $(n=10)$ or CEmOC $(n=2)$ exceeded the required number per available population. The geographical distribution of the facilities was good but the quality of services offered was poor especially at the BEmOC facilities. Almost all researchers from sub Saharan Africa have also shown this disparity where CEmOC are functioning while BEmOC facilities consistently offer a range of 1-3 signal functions [14-18]. Ameh et al (2012) showed that only $2-6 \%$ of BEmOC facilities were fully functional while Oyerinde et al (2011) observed that less than $40 \%$ of facilities could offer parenteral anticonvulsants or manual removal of placenta $[15,16]$. In Hai district only $20 \%$ of BEmOC facilities could offer magnesium sulphate, a serious situation given eclampsia \& preeclampsia are second leading cause of maternal deaths in Tanzania [1].

Signal functions that requires investment in training the health providers were least performed. For example newborn resuscitation using bag and mask could only be performed in one out of ten designated BEmOC facilities while life-saving procedures of removal of retained products or manual removal of retained placenta were not available. Lack of knowledge and skills of health providers in EmOC [16, 17], insufficient equipment and supplies including drugs, poor physical infrastructures of lower facilities that offer BEmOC are some attributed factors to poor quality of services offered $[10,18]$. Tanzania has made insufficient progress in reducing maternal and newborn deaths to meet the 2015 MDG goal 
[11] hence there is a need to prioritize and scale up interventions like competence training in EmOC for health providers of lower facilities and rural areas. This should go hand in hand with strengthening logistic and supply chain system.

The study observed the proportion of expected births taking place in the facilities was $65.3 \%$, higher than the recommended UN level. Also met need for EmOC was high $94 \%$ and $\mathrm{C} / \mathrm{S}$ (7\%) have met the UN recommended levels [7] The findings in this district are contrary to other studies where deliveries in EmOC are lower (9\% - 47\%) and met need for EmOC is also low $(6 \%-50 \%)[15,16,19]$. This may be explained by the fact that Kilimanjaro region already has high coverage on indicators for reproductive, maternal, newborn and child health compared to other regions or nation level [6]. Or maybe the intense education and campaigns which emphasize the importance of women to deliver in health facilities are taken positively in this area. These results mean in this district, women do come to the health facilities both for normal deliveries and when they have obstetric complications. It is the health system i.e. BEmOC which fails to meet the standards and has to improve so that women and families do not lose faith or trust and seek care elsewhere [9].

The fact that there was no case of maternal death reported needs to be interpreted with caution. It maybe the district has well organized network of referral system and the patients can be transferred to tertiary care in timely manner. It takes about 40 minutes from Hai district to KCMC Referral hospital, so the proximity of the district to the Referral facility may have contributed to the observed situation. Quality of care may also improve survival. In this study, of the 12 facilities surveyed, 9 had quality improvement committees which performed the audits quarterly.

For provision of quality services, trained health personnel are required. What was noted in this study was maldistribution of health providers with many of providers being at hospital level with a huge work load in the health centres and dispensaries. This human resource challenge has been reported by others where by the lower facilities which are mostly in rural tend to have the least trained personnel compared to hospitals which are most in urban areas $[9,10]$. While Tanzania has developed human resource strategic plan addressing among other things motivation and retention in rural and hard to reach areas [20], programs like payment for performance (P4P) might be used as one of the incentives The study had limitation; it was conducted in one district of the country which is located in a region with somewhat better $\mathrm{RCH}$ care indicators as compared to other districts [6]. The situation in other regions or districts outside the region may be very different, making it difficult to generalize the results to other settings.

\section{Conclusion}

With only approximately 200 days left to reach the MDG targets, the country needs an accelerated and targeted strategy to improve availability of basic EmOC. Quality improvement of EmOC services offered is also needed. Enhancing health care providers skills in EmOC and overall sexual and reproductive health through training and mentoring as well as enabling environment is needed.

\section{Acknowledgement}

The authors thank the District Medical Officer and leaders of the health facilities in Hai district for permission and cooperation during data collection.

\section{References}

[1] WHO \& UNICEF (2014). Countdown to 2015 Report (2014); Maternal, Newborn and Child Survival; Fulfilling the Health Agenda for Women and Children. May, 2014. http://www.countdown2015mnch.org/

[2] Ronsmans C, \& Graham W. Maternal mortality: Who, when, where and why. Lancet 2006, 368: 1189-1200.

[3] WHO (2011). World health statistics 2011. Geneva: World Health Organization.

[4] National Bureau of Statistics (NBS) and ORC Macro: Tanzania Demographic and Health Survey 2004-05. Dar es Salaam, Tanzania 2005.

[5] MOHSW (2008). The National Road Map Strategic Plan to Accelerate Reduction of Maternal, Newborn and Child Deaths in Tanzania: 2008-2015. One Plan. RCHS, Directorate of Preventive Services, United Republic of Tanzania, Dar es Salaam, April, 2008.

[6] National Bureau of Statistics (NBS) and ICF Macro: Tanzania Demographic and Health Survey, 2010. Dar es Salaam, Tanzania 2011.

[7] WHO (2009) Monitoring emergency obstetric care. A handbook. WHO, UNFPA, UNICEF \& AMDD. Geneva, Switzerland: WHO press. http://whqlibdoc.who.int/publications/2009/9789241547734_e ng.pdf

[8] WHO. (2004).Making pregnancy safer: the critical role of the skilled attendant. A joint statement by WHO, ICM and FIGO. Geneva, Switzerland: WHO press

[9] MOHSW (2014). Mid Term Review of the National Road Map Strategic Plan to Accelerate Reduction of Maternal, Newborn and Child Deaths in Tanzania: 2008-2015. One Plan. RCHS, Directorate of Preventive Services, United Republic of Tanzania, Dar es Salaam, April, 2014.

[10] MOHSW (2013). Tanzania Service Availability and Readiness Assessment (SARA) 2012: Final Report. Dar es Salaam, Tanzania, March 2013.

[11] MOHSW (2014). The National Road Map Strategic Plan to Accelerate Reduction of Maternal, Newborn and Child Deaths in Tanzania: 2008-2015. Sharpened One Plan. RCHS, Directorate of Preventive Services, United Republic of Tanzania, Dar es Salaam, April, 2014.

[12] National Bureau of Statistics, Dar es Salaam and Office of Chief Government Statistician, Zanzibar, 2013. 2012 Population and Housing Census. NBS, March 2013. 
[13] Kwesigabo G \& Mwangu MA. Tanzania's health system and workforce crisis. , 33(S1), pp.S35-S44. Available at: http://dx.doi.org/10.1057/jphp.2012.55.

[14] Kongnyuy EJ, Hofman J, Mlava G, Mhango C, van den Broek N. Availability, Utilisation and Quality of Basic and Comprehensive Emergency Obstetric Care Services in Malawi. Matern Child Healt J 2009, 13: 687-694.

[15] Ameh C, Msuya S, Hofman J, Raven J, Mathai M, et al. (2012) Status of Emergency Obstetric Care in Six Developing Countries Five Years before the MDG Targets for Maternal and Newborn Health. PLoS ONE 2012, 7(12): e49938. doi:10.1371/journal.pone.0049938

[16] Oyerinde K, Harding Y, Amara P, Kanu R, Shoo R, et al. et al. The status of maternal and newborn care services in Sierra Leone 8 years after ceasefire. International Journal of Gynaecology and Obstetrics 2011, 114(2): 168-73.
[17] Ueno E, Adegoke AA, Masenga G, Fimbo J, Msuya SE. Skilled Birth Attendants in Tanzania: A Descriptive Study of Cadres and Emergency Obstetric Care Signal Functions Performed Maternal and Child Health J 2014, 18(4): doi: DOI 10.1007/s10995-014-1506-z.

[18] Paxton A, Bailey P, \& Lobis S. The United Nations Process Indicators for emergency obstetric care: Reflections based on a decade of experience. International Journal of Gynaecology and Obstetrics 2006, 95(2): 192-208.

[19] Gabrysch, S., Zanger, P., \& Campbell, O. M. R. (2012). Emergency obstetric care availability : a critical assessment of the current indicator, 17(1), 2-8. doi:10.1111/j.13653156.2011.02851.x.

[20] MOHSW (2008). Human Resource for Health Strategic Plan, 2008-2013. United Republic of Tanzania, Dar es Salaam, Tanzania. 